\title{
3D Finite Element Analysis to Assess the Stress Distribution Pattern in Mandibular Implant-supported Overdenture with Different Bar Heights
}

\author{
Shikha Joshi ${ }^{1}$, Sandeep Kumar ${ }^{2}$, Shashikala Jain ${ }^{3}$, Rajnish Aggarwal ${ }^{4}$, Sunita Choudhary ${ }^{5}$, Nandalur K Reddy ${ }^{6}$
}

\begin{abstract}
Aim: Proper stress distribution on dental implants is necessary in bar-retained implant overlay dentures. The purpose of the study is to comparatively assess the stress distribution pattern on the crestal bone at the bone-implant interface due to different bar heights using finite element models (FEMs).

Materials and methods: Eight 3D FEMs were developed from mandibular overdentures with two implants in the canine region separated by a distance of $20 \mathrm{~mm}$. In these models, four different bar heights from the mucosa $(0.5,1,1.5$, and $2 \mathrm{~mm})$ with $12 \mathrm{~mm}$ occlusal plane height were analyzed. A unilateral and a bilateral vertical load of $150 \mathrm{~N}$ were applied to the central occlusal fossa of the first molar and the stress of bone around the implant was analyzed by finite element analysis (FEA).

Results: By increasing the bar height, the maximum stress values around implants on the crestal bone were found to be increased in unilateral and bilateral loading models. In unilateral loading models, the maximum stress was found in a model with a $2 \mathrm{~mm}$ bar height ( $0.46 \mathrm{MPa})$ on the distal side of the ipsilateral implant, and in bilateral loading cases, the maximum stress was also found in a model with a $2 \mathrm{~mm}$ bar height (0.456 MPa).

Conclusion: As the vertical cantilever increases (here the bar height), the maximum stress on the crestal bone increases. A minimum of $0.5 \mathrm{~mm}$ of space is sufficient between the mucosa and the inferior border of the bar to maintain oral hygiene.

Clinical significance: From the present study, it can be concluded that an increase in bar height causes an increase in stress levels on the periimplant crestal bone.

Keywords: Bar heights, Dental implants, Finite element analysis, Overdenture, Stress analysis.

The Journal of Contemporary Dental Practice (2019): 10.5005/jp-journals-10024-2599
\end{abstract}

\section{INTRODUCTION}

Loss of teeth is a multifactorial and often a complex interaction of multiple comorbidities that, when left unresolved, may progress to a state of complete edentulism. Edentulism is a condition of being without natural teeth and represents a terminal process. ${ }^{1}$

The prosthetic management of a patient with complete loss of teeth has always been a major challenge. Complete maxillary and mandibular dentures have been the standard of choice for such patients. However, most often patients complain of adapting to their mandibular denture due to a lack of comfort, retention, stability, and inability to masticate. Initially, endosseous implants, most often, four to six implants in combination with a fixed prosthesis were the treatment of choice. It proved quite successful. Implant overdenture treatment was adopted later, and long-term clinical results were shown to be excellent as well. ${ }^{2}$ Most patients were satisfied with the improvement in the retention and stability of the mandibular denture and decrease of oral soreness and had no objections to removable prostheses and do not desire complete fixed prostheses due to their more difficult oral hygienic procedures.

In comparison to the implant-supported fixed prosthesis, the implant-retained overdentures require fewer implants, less invasive and less expensive surgical procedure, and simplified laboratory procedures by using a premanufactured retention system with lower costs, thus, making the treatment more accessible to a higher number of edentulous patients. ${ }^{3}$ They also have the advantage of allowing easier cleaning as they are removable and supported by a fewer number of implants.
${ }^{1-5}$ Department of Prosthodontics, Surendera Dental College and Research Institute, Sri Ganganagar, Rajasthan, India

${ }^{6}$ College of Dentistry, Jazan, Kingdom of Saudi Arabia

Corresponding Author: Sandeep Kumar, Department of Prosthodontics, Surendera Dental College and Research Institute, Sri Ganganagar, Rajasthan, India, Phone: +91 9024606318, e-mail: mdssandy07@gmail.com

How to cite this article: Joshi S, Kumar S, et al. 3D Finite Element Analysis to Assess the Stress Distribution Pattern in Mandibular Implant-supported Overdenture with Different Bar Heights. J Contemp Dent Pract 2019;20(7):794-800.

Source of support: Nil

Conflict of interest: None

Mandibular implant-supported overdentures are usually retained by ball attachments, clip-on bar connecting the implants, or magnetic attachments. The forces and stresses that are generated by these retentive attachments are different from those seen with natural teeth supported by the periodontal ligament. If the stresses generated by these attachments exceed the physiological limit, they may lead to several undesirable results. ${ }^{4}$

For a successful implant-retained overdenture, adequate restorative space is an important factor. The available restorative space in the case of edentulous patients is bounded by the supporting tissues of the edentulous jaw, cheeks, lips, tongue, and 
the occlusal plane. Other factors must also be considered when defining available restorative space, such as interocclusal distance, phonetics, and esthetics. When considering any removable prosthesis with mobility and soft-tissue support, two height levels must be remembered, the first is the height of the attachment system to the crest of the bone, and the second is the distance from the attachment to the occlusal plane. ${ }^{5}$

A good prognosis requires a correct selection of the attachment system based not only on retention or cost aspects but also on biomechanics aspects, as it is the most fragile link between prosthesis and implant. The most common attachments that have been used are independent connections to each implant abutment with O-rings or splinting of implants with bar/clip attachments. Bar supported overdenture is a popular choice because of its load sharing.

In bar-supported overdentures, the bar height is one of the most influencing factors in the magnitude of the load transferred to the implants. The stress around dental implant systems is analyzed using several methods, including photo-elastic study, FEA, and strain gauges on bony surfaces. FEA offers several advantages over the other methods, including accurate representation of complex geometries, easy model modification, and the representation of the internal stress and other mechanical quantities. ${ }^{6}$

The aim of the present study is to evaluate the stress magnitude and distribution on the crestal bone around implant-retained, barsupported overdentures with bar heights at $0.5 \mathrm{~mm}, 1 \mathrm{~mm}, 1.5 \mathrm{~mm}$, and $2 \mathrm{~mm}$ and to evaluate the most biomechanically favorable bar height with a minimum stress at the peri-implant crestal bone using FEA.

\section{Materials and Methods}

Edentulous patients with severely resorbed mandibles may experience problems with conventional dentures because of impaired load-bearing capacity, and this result related to discomfort and patient dissatisfaction. To improve the support, stability, and retention, osseointegrated implants have been used. At present, the placement of two implants and the fabrication of an implantretained overdenture are considered by some to be the treatment of choice. An implant overdenture provides prosthesis stability and enables the patient to consistently reproduce centric occlusion (Jemt and Stalblad, 1986). Different attachment types are currently being used to provide proper support for the implant-retained overlay dentures. Many types of attachments such as bar, ball, and magnet are used. However, guidelines for the selection of appropriate attachments required for the denture retention and stability depending on the cases are insufficient. ${ }^{7}$ The purpose of this study is to evaluate the stress distribution pattern on the periimplant crestal bone with different bar heights.

In the present in vitro study, eight geometric models were created using computer-aided three-dimensional interactive application (CATIA) program (version 12) and then converted into 3D FEMs by the using Hypermesh software 7.0, to represent an edentulous human mandible with overdentures retained by bar attachment systems at different heights from the mucosa. The model included mucosa, cortical bone, cancellous bone with two implants distributed over the canine region, and an overdenture retained by bar attachment. Each model was constrained at the base of the cancellous bone. The models were then subjected to a 150-N vertical unilateral load (Fig. 1A) and bilateral load (Fig. 1B) representing the masticatory force applied to the central occlusal fossa of the first molar of the prosthesis. The analysis was carried out using the ANSYS (analysis system) software (version 12) to evaluate the resultant Von Mises stress induced on the crestal bone.

\section{Model Designing \\ Development of Various Components of the Model}

Each component was designed separately and then assembled. The mandibular residual ridge of each model was represented by moderate resorption. The mandibular model consisted of three layers, the mucosa, the underlying cortical bone, and cancellous bone. This residual ridge supported the implants with the overlying attachments and the prosthesis. Two titanium implants (ITI, Straumann Dental India LLP) of a length of $16 \mathrm{~mm}$ and a diameter of $4.2 \mathrm{~mm}$ were modeled to be placed in the canine tooth position bilaterally. The implants were set $20 \mathrm{~mm}$ apart. Transmucosal abutments were modeled with a diameter of $5.5 \mathrm{~mm}$ and a height of $4.8 \mathrm{~mm}$ at the canine position over the implants. Bar attachment (Hader bar which is round in shape has $20 \mathrm{~mm}$ length and $1 \mathrm{~mm}$ diameter) was considered in this study at four different heights, i.e., at a distance of $0.5 \mathrm{~mm}, 1 \mathrm{~mm}, 1.5 \mathrm{~mm}$, and $2 \mathrm{~mm}$ from the mucosa. Bar-supported acrylic overdenture was modeled with an occlusal plane height of $12 \mathrm{~mm}$ from the mucosa. A clip was modeled over the bar and embedded in the corresponding region on the intaglio surface of the denture.
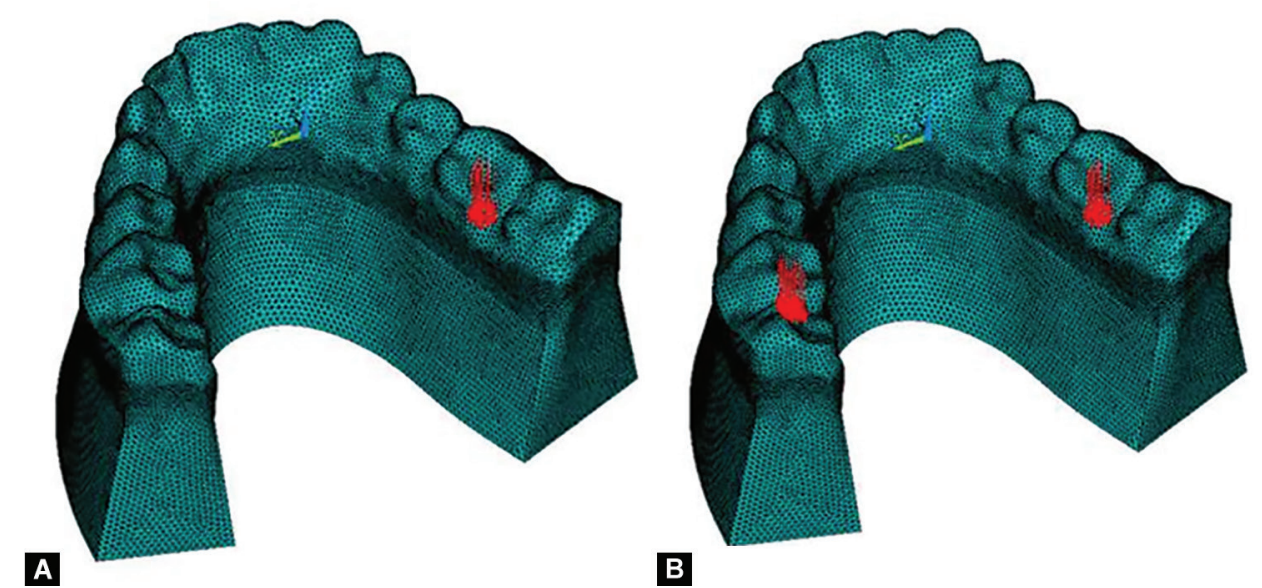

Figs $1 \mathrm{~A}$ and $\mathrm{B}$ : (A) $150 \mathrm{~N}$ force acting at the vertical direction unilaterally; (B) $150 \mathrm{~N}$ force acting at vertical direction bilaterally 


\section{Stress Analysis}

\section{Meshing}

The creation of FEM was the next step. The model was subdivided into similar geometric shapes or elements whose apexes meet to form nodes. This is known as the meshing of the model and was done with the computer program-Hypermesh 7.0. Such elements and their nodes remained in contact irrespective of the size and nature of stresses generated in a computer simulation. The nodes and materials for the models are tabulated in Table 1.

All the materials were assumed to be homogenous, linearly elastic, and isotropic. The material properties of the dentures, mucosa, cortical bone, cancellous bone, implants, and attachments are then incorporated. All conditions are set and the analysis is carried out by using the ANSYS software, version 12. The material properties are tabulated in Table 2.

\section{Loading}

A functional force analogous to occlusal loading of $150 \mathrm{~N}$ was applied unilaterally and bilaterally at the central fossa of the first molar (center of mastication) ${ }^{8}$ and the stress patterns produced under such loading within the models across various components were measured.

\section{Analyses}

Following loading, the maximum Von Mises stress at the implantbone interface and along the different layers in all the models was assessed using the finite element program (ANSYS software, version 12).

\section{Results}

The present 3D finite element study was performed to evaluate and compare the stresses induced at the crestal bone due to various bar heights in an implant-supported overdenture.

A total of eight mandibular implant-retained overdenture models were designed. Models I and II represent an overdenture

Table 1: The nodes and elements for the models

\begin{tabular}{lll}
\hline Model & Nodes & Element \\
\hline Model I & 86225 & 427497 \\
Model II & 86225 & 427497 \\
Model III & 95283 & 482104 \\
Model IV & 95283 & 482104 \\
Model V & 86653 & 429947 \\
Model VI & 86653 & 429947 \\
Model VII & 86643 & 429988 \\
Model VIII & 86643 & 429988 \\
\hline
\end{tabular}

Table 2:Young's modulus and Poison's ratio of materials used in the study

\begin{tabular}{llll}
\hline S.no. & Material & $\begin{array}{l}\text { Young's modulus } \\
(\mathrm{E})(\mathrm{MPa})\end{array}$ & $\begin{array}{l}\text { Poison's } \\
\text { ratio }(\mathrm{V})\end{array}$ \\
\hline 1 & Cortical bone & $1.37 \times 10^{10}$ & 0.30 \\
2 & Cancellous bone & $1.37 \times 10^{9}$ & 0.30 \\
3 & Mucosa & $1.0 \times 10^{7}$ & 0.40 \\
4 & Acrylic resin & $2.7 \times 10^{9}$ & 0.35 \\
5 & Titanium & $1.17 \times 10^{11}$ & 0.33 \\
6 & Gold & $1.0 \times 10^{11}$ & 0.3 \\
\hline
\end{tabular}

retained by two splinted implants with a bar attachment at a height of $0.5 \mathrm{~mm}$ from the mucosa with a unilateral and bilateral force, respectively. Models III and IV represent an overdenture retained by two splinted implants with a bar attachment at a height of $1 \mathrm{~mm}$ from the mucosa with a unilateral and bilateral force, respectively. Models V and VI represent an overdenture retained by two splinted implants with a bar attachment at a height of $1.5 \mathrm{~mm}$ from the mucosa with a unilateral and bilateral force, respectively. Models VII and VIII represent an overdenture retained by two splinted implants with a bar attachment at a height of $2 \mathrm{~mm}$ from the mucosa with a unilateral and bilateral force, respectively. These models were then subjected to a load of $150 \mathrm{~N}$ vertically on the first molar. Loading stresses were induced at the implant-bone interface. These stress color plots obtained were studied and the maximum Von Mises stress induced at the bone-implant interface was compared and tabulated in Tables 3 and 4. Table 3 and Figure 2 describe the evaluation and comparison of stresses on the crestal bone due to the unilateral force on different bar heights. Table 4 and Figure 3 describe the evaluation and comparison of stresses due to the bilateral force on the crestal bone due to different bar heights.

\section{Discussion}

As life spans lengthen, a significant number of people outlive their teeth. Treating older patients, especially those with disabilities, has always been a major challenge. Edentulous patients generally complain of lack of retention and stability of dentures. Lack of retention was common in the mandibular denture when compared to the excellent retention of the maxillary denture. ${ }^{9}$

To overcome this, implant overdentures have become one of the most preferred options for treating completely edentulous patients because of minimal invasiveness, a lower number of implants used, and its relative simplicity. The advantages of implantretained prostheses include improved mastication, increased passive tactile sensitivity, and better retention compared to the conventional ones.

Table 3: Evaluation and comparison of stresses on the crestal bone due to unilateral force on different bar heights

\begin{tabular}{llllll}
\hline & \multicolumn{4}{c}{ Maximum stress $(\mathrm{MPa})$} \\
\cline { 2 - 3 } $\begin{array}{l}\text { Bar height } \\
(\mathrm{mm})\end{array}$ & \multicolumn{3}{c}{ Ipsilateral side } & & \multicolumn{2}{c}{ Contralateral side } \\
\cline { 2 - 3 } \cline { 5 - 6 } & Mesial & Distal & & Mesial & Distal \\
\hline 0.5 & 0.283 & 0.372 & & 0.16 & 0.052 \\
1 & 0.318 & 0.380 & & 0.182 & 0.082 \\
1.5 & 0.391 & 0.428 & & 0.271 & 0.169 \\
2 & 0.421 & 0.46 & & 0.278 & 0.197 \\
\hline
\end{tabular}

Table 4: Evaluation and comparison of stresses on the crestal bone due to bilateral force on different bar heights

\begin{tabular}{llllll}
\hline \multirow{2}{*}{$\begin{array}{l}\text { Bar height } \\
(\mathrm{mm})\end{array}$} & \multicolumn{3}{c}{ Right side } & & \multicolumn{2}{c}{ Left side } \\
\cline { 2 - 3 } \cline { 5 - 6 } & 0.5 Mesial & Distal & & Mesial & Distal \\
\hline 1 & 0.281 & 0.368 & & 0.187 & 0.213 \\
1.5 & 0.322 & 0.371 & & 0.284 & 0.328 \\
2 & 0.379 & 0.401 & & 0.341 & 0.367 \\
\hline
\end{tabular}




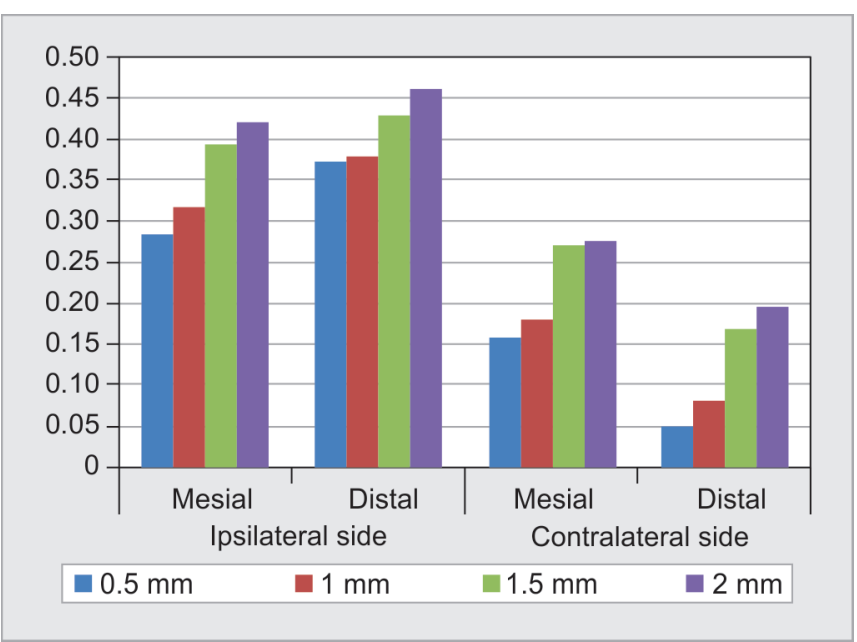

Fig 2: Comparison of maximum Von Mises stresses in an implantsupported overdenture retained by bar attachment at various heights due to unilateral force

Different attachment types are currently being used to provide proper support for the implant-retained overlay dentures. Certain authors have reported superior stress distribution with the application of implant-retained mandibular ball-supported overlay dentures compared with bar-supported dentures. Others believe that ball attachments should be used in the short term as a transitional phase. Based on their studies, it may be better to use implant-retained mandibular bar-supported overlay dentures in the long term because bar attachments have shown more appropriate stress distribution. ${ }^{10}$

According to some authors, ${ }^{10-12}$ if one looks at the overall stress distribution, the bar/clip attachment system seems to perform better than the ball/O-ring attachment system, as the forces are distributed better. The rationale of implant splinting was that it would decrease stresses due to increased prosthesis stability. ${ }^{5}$ Hence, bar attachments have been chosen for the study.

Excess stress at the bone-implant interface usually results in the crestal bone loss and early implant failure. Therefore, the design of implant-supported overlay dentures should ensure proper stress distribution to the bone around implants. As to the best of our knowledge, there is very little literature available regarding the nature of force transmission comparing different bar heights in a mandibular implant-supported overdenture.

In the present study, a 3D FEA method was conducted to investigate the stresses induced by using different bar heights in the supporting bone in a mandibular implant-retained overdenture.

For predicting the effects of stress on implant and surrounding bone, FEA has become an increasingly useful tool. Thus, it has become an effective computational tool that has been adapted from the engineering arena to dental implant biomechanics. It is an accepted theoretical technique used in the solution of engineering problems and offers many advantages over other methods in considering the complexities that characterize actual clinical situations. ${ }^{10,13}$ Most FEA models assume a state of the optimal osseointegration, meaning that cortical and cancellous bones are assumed to be perfectly bonded to the implant. This usually does not occur so exactly in clinical situations. However, Papavasiliou et al. concluded that the degree of osseointegration had not affected the stress levels or distributions for axial or oblique loads in FEM

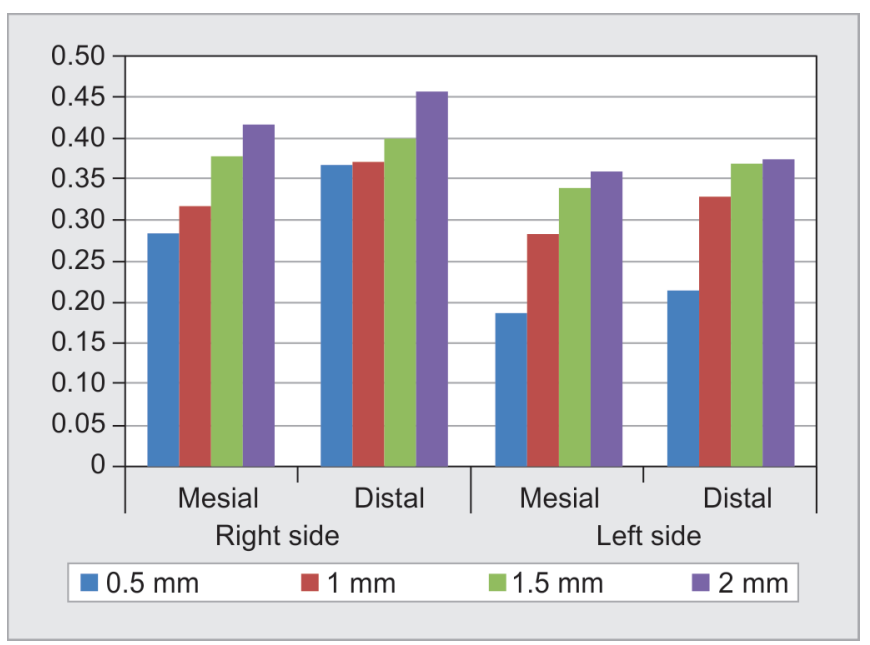

Fig 3: Comparison of maximum Von Mises stresses in an implantsupported overdenture retained by bar attachment at various heights due to bilateral force

analysis. ${ }^{13}$ Therefore, it is considered to be an appropriate method for stress analysis which is used in the present study.

There are two types of FEA, static analyses and dynamic analyses. The maximum closure speed of the mandible relative to the maxilla vary depending on the methods used for its measurements between 85 and $140 \mathrm{~mm} / \mathrm{s}$, if higher mandibular velocities are involved, for example, during inadvertent biting of a hard object, a dynamic analysis may be required. A static analysis is considered suitable to simulate clenching and grinding, and in masticatory conditions. So, static loads are considered to be sufficient for the purpose of this study.

A very few studies investigated the stress distribution capacity of these attachment systems with bar attachment at different heights. The present study focused on the stresses and the variations induced at the crestal bone using an implant with bar/clip attachment at various heights of $0.5 \mathrm{~mm}, 1 \mathrm{~mm}, 1.5 \mathrm{~mm}$, and $2 \mathrm{~mm}$.

For the purpose of this study, eight 3D geometric models were created using the 3D CATIA program (version 5) and then converted into 3D FEMs by using the Hypermesh software, to represent an edentulous human mandible. The dimensions of the mandible model were taken from a finite element study conducted by Behnaz Ebadian et al. ${ }^{8}$ It simulated a moderately resorbed residual ridge. The model included the mucosa, cortical bone, and cancellous bone with two implants in the canine region with an overdenture retained by bar/clip attachment at various heights.

After designing, each model was meshed using the Hypermesh software to eight nodded solid brick elements. All materials were assumed to be homogenous, linearly elastic, and isotropic. The respective material properties were then assigned to each component. The 3D model behaved as a virtual human mandible supporting an implant overdenture retained by bar/clip attachment.

After modeling, a static load of $150 \mathrm{~N}$ was applied on the first molar tooth region. In the literature, masticatory force in the molar site ranges from 50 to $150 \mathrm{~N}^{8}{ }^{8}$ Hence, a vertical load of $150 \mathrm{~N}$ was applied on the first molar.

Analysis of the stresses on all the models was done using the ANSYS software. The stresses were displayed in different colors on the model. The warmer the colors, more were the stresses on them. Therefore, observing the colors, stresses were assessed. Each color 
had a particular range of stress values. The highest and the lowest values of stresses for each color were given under the scale which contained all the colors from blue to red.

The maximum Von Misses stresses were evaluated and tabulated in Tables 3 and 4 and compared the unilateral and bilateral stresses, respectively, on the crestal bone around implants with bar heights at $0.5 \mathrm{~mm}, 1 \mathrm{~mm}, 1.5 \mathrm{~mm}$, and $2 \mathrm{~mm}$ from the mucosa under vertical loading.

Models I, III, V, and VII are implant-supported overdentures with unilateral force retained by bar attachments at the heights of 0.5 $\mathrm{mm}, 1 \mathrm{~mm}, 1.5 \mathrm{~mm}$, and $2 \mathrm{~mm}$, respectively, that had shown the maximum stress distribution of $0.372 \mathrm{MPa}, 0.380 \mathrm{MPa}, 0.428 \mathrm{MPa}$, and $0.46 \mathrm{MPa}$ on distal aspect of the implant at the crestal bone as shown in Figures $4 A, 5 A, 6 A$, and $7 A$, respectively. Due to unilateral loading, maximum stress occurred on the ipsilateral fixture which was in agreement with various other authors. ${ }^{6,14}$ The results are tabulated in Table 3. On comparison, maximum stress concentration was seen at the bone-implant interface in implant-supported overdentures with bar attachments at a height of $2 \mathrm{~mm}(0.46 \mathrm{MPa})$ followed by $1.5 \mathrm{~mm}$ height $(0.428 \mathrm{MPa})$, then 1 $\mathrm{mm}$ height $(0.380 \mathrm{MPa})$, and $0.5 \mathrm{~mm}(0.372 \mathrm{MPa})$. Models II, IV, VI, and VIII are implant-supported overdentures with bilateral force retained by bar attachments at heights of $0.5 \mathrm{~mm}, 1 \mathrm{~mm}, 1.5 \mathrm{~mm}$ and $2 \mathrm{~mm}$, respectively, that had shown the maximum stress distribution of $0.368 \mathrm{MPa}, 0.371 \mathrm{MPa}, 0.401 \mathrm{MPa}$, and $0.456 \mathrm{MPa}$ on distal aspect of implant at the crestal bone on the right side as shown in Figures 4B, 5B, 6B, and 7B, respectively. The maximum stress varied on the left side which may be due to modeling errors. The results are tabulated in Table 4. It was noticed that when the bar height increases, the maximum stress values on the crestal bone increases. This implies that as vertical cantilever increases, the maximum stress on the crestal bone increases. A minimum of $0.5 \mathrm{~mm}$ of space is sufficient between the mucosa and the inferior border of the bar to maintain oral hygiene.

From the present study, it can be concluded that an increase in bar height causes an increase in stress levels on the peri-implant crestal bone. But there are studies that support that at a bar height of $0 \mathrm{~mm}$, a maximum stress is induced at the crestal bone due to a
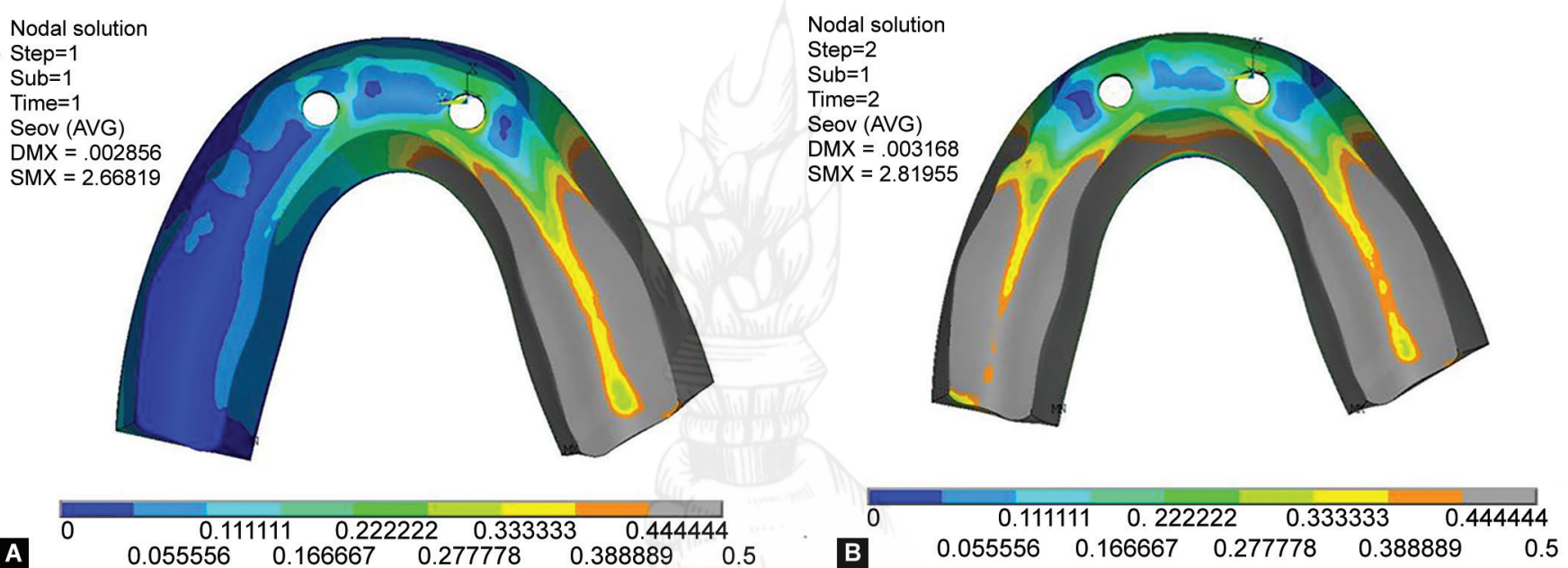
$\begin{array}{lllll}0.055556 & 0.166667 & 0.277778 & 0.388889 & 0.5\end{array}$

\section{B}

$\begin{array}{llll}0.055556 & 0.166667 & 0.277778 & 0.388889\end{array}$

0.5

Figs 4A and B: (A) Von Mises stresses induced at the bone-implant interface using an implant with a bar attachment at a height of $0.5 \mathrm{~mm}$ from the mucosa due to unilateral force (model I); (B) Von Mises stresses induced at the bone-implant interface using implant with a bar attachment at a height of $0.5 \mathrm{~mm}$ from the mucosa due to bilateral force (model II)

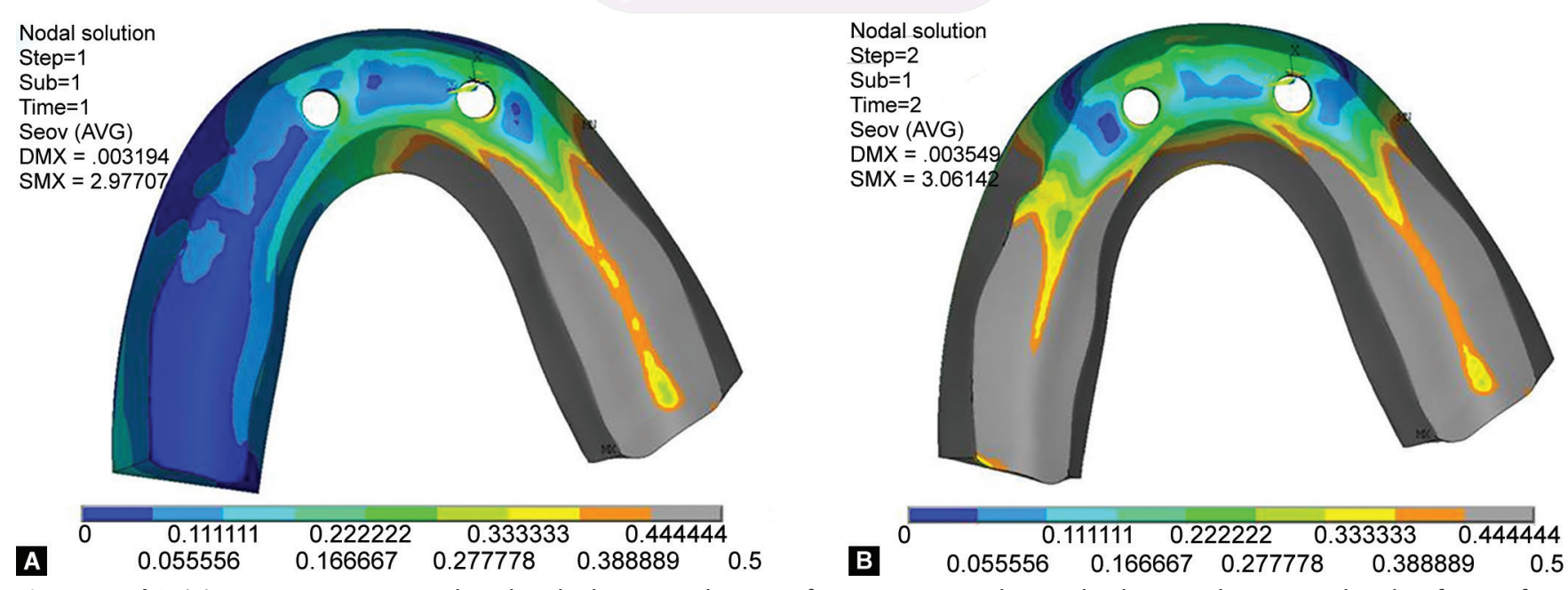

Figs 5A and B: (A) Von Mises stresses induced at the bone-implant interface using an implant with a bar attachment at a height of $1 \mathrm{~mm}$ from the mucosa due to unilateral force (model III); (B) Von Mises stresses induced at the bone-implant interface using implant with a bar attachment at a height of $1 \mathrm{~mm}$ from the mucosa due to bilateral force (model IV) 

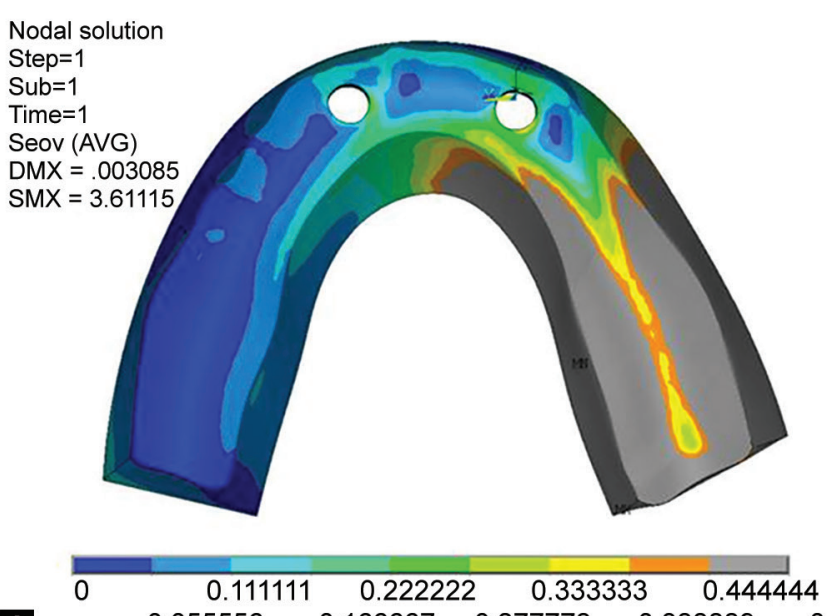

\section{A} $\begin{array}{lllll}0.055556 & 0.166667 & 0.277778 & 0.388889 & 0.5\end{array}$
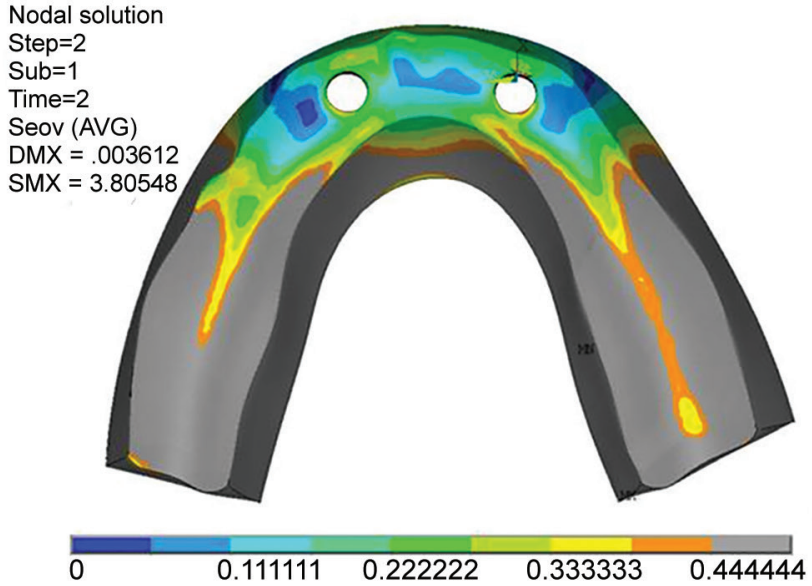

Figs 6A and B: (A) Von Mises stresses induced at the bone-implant interface using an implant with a bar attachment at a height of $1.5 \mathrm{~mm}$ from the mucosa due to unilateral force (model V); (B) Von Mises stresses induced at the bone-implant interface using an implant with a bar attachment at a height of $1.5 \mathrm{~mm}$ from the mucosa due to bilateral force (model $\mathrm{VI}$ )

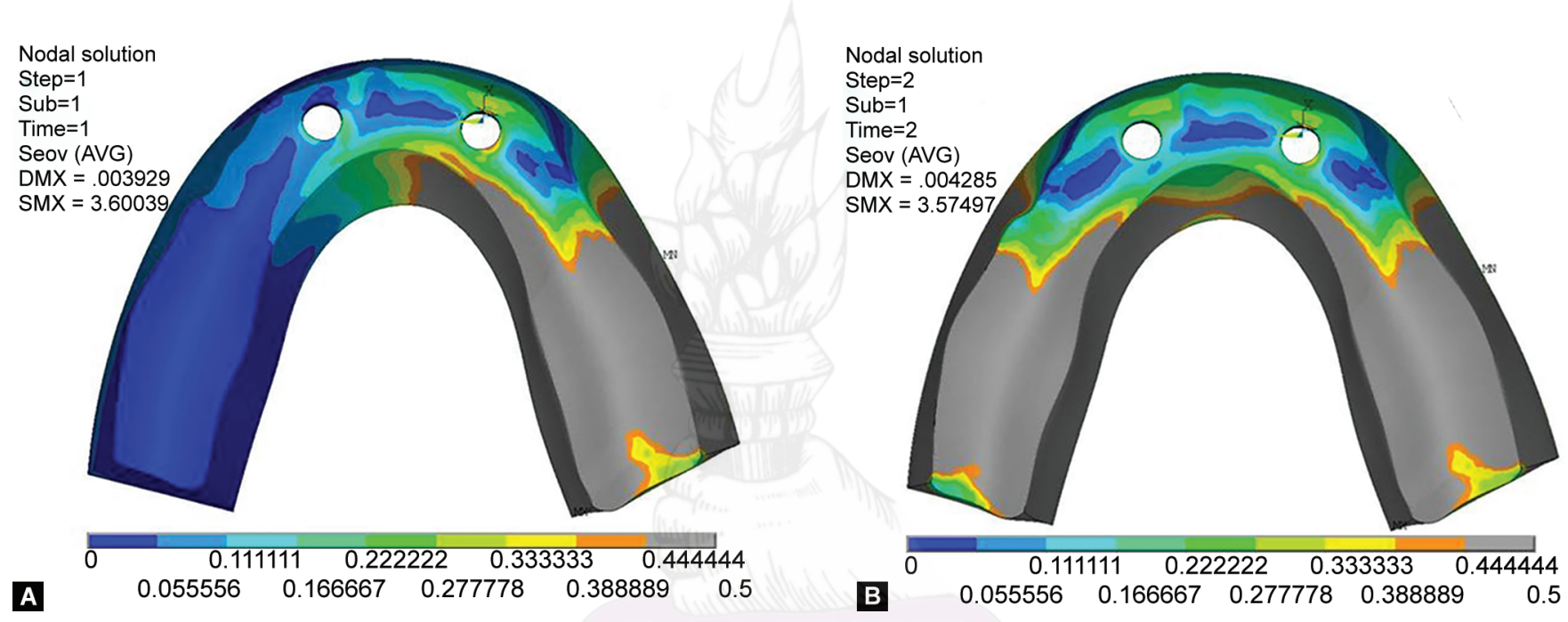

Figs 7A and B: (A) Von Mises stresses induced at the bone-implant interface using an implant with a bar attachment at a height of $2 \mathrm{~mm}$ from the mucosa due to unilateral force (model VII); (B) Von Mises stresses induced at the bone-implant interface using an implant with a bar attachment at a height of $2 \mathrm{~mm}$ from the mucosa due to bilateral force (model VIII)

direct contact to the mucosa and the bone. ${ }^{6}$ So while considering a bar attachment, a minimum value of the bar height $(0.5 \mathrm{~mm})$ is necessary to maintain hygiene and which is not in direct contact with the mucosa must be appreciated.

The numeric values that have been reported in this study must be considered as biomechanical indications within the limitations of the model presented. This is because 3D FEMs represent a simplification of the investigated structures. It should also be emphasized that the aim of the study is not to report the absolute values of stress but to compare the stress levels on the crestal bone at various heights of bar attachment from the mucosa.

This study has certain limitations. The first limitation is that the vital anisotropic tissues were considered isotropic. Second, the loads applied were vertical static loads. They were different from dynamic loads that are seen during the function. There are also limitations when predicting the response of biological systems to applied loads, as with all the modeling systems, including photoelastic analysis and strain gauge measurements. Hence, FEA should not be considered alone even though it provides a sound theoretical basis of understanding the behavior of a structure in a given environment. Actual experimental techniques and clinical trials should follow FEA to establish the influence of observed stress levels on the tissue and prosthesis function. ${ }^{15}$

\section{Conclusion}

Under the limitations of the present FEA study, the following conclusions were drawn:

- A bar height of $0.5 \mathrm{~mm}$ induced the least stress on the crestal bone.

- A bar height of $2 \mathrm{~mm}$ induced the maximum stress on the crestal bone.

Considering the results obtained, it can be inferred that an implant-supported overdenture retained by the bar attachment at a height of $0.5 \mathrm{~mm}$ favored more equitable load distribution to 
the peri-implant crestal bone when compared to bar attachment at increased heights. It can be concluded that by increasing the bar height stresses onto the bone increases. So, in cases with a bar-supported overdenture, the height of the bar from the mucosa should be as minimum as possible within the desired limit.

\section{References}

1. Bagde $A D$, Jaju $S B$, et al. A review on FEM analysis of mandibular overdenture implant. Int J Innov Res Sci Eng Technol 2013;2(6): 2137-2144.

2. Cune $M$, Burgers $M$, et al. Mandibular overdenture retained by two implants: 10 year results from a crossover clinical trial comparing ball-socket and bar-clip attachments. Int J Prosthodont 2010;23(4): 310-317.

3. Barao VAR, Assunsao WG, et al. Finite element analysis to compare complete denture and implant-retained overdentures with different attachment systems. J Craniofac Surg 2009;20(4):1066-1071. DOI: 10.1097/SCS.0b013e3181abb395.

4. El-Anwar MI, Mohammed MS. Comparison between two low profile attachments for implant mandibular overdentures. J Genet Eng Biotechnol 2014;12:45-53.

5. Ebadian B, Talebi S, et al. Stress analysis of mandibular implantretained overdenture with independent attachment system: effect of restoration space and attachment height. Gen Dent 2015;63(1):61-67.

6. Rismanchian M, Dakhilalian M, et al. Implant-retained mandibular bar-supported overlay dentures: a finite element stress analysis of four different bar heights. J Oral Implantol 2012;38(2):133-139. DOI: 10.1563/AAID-JOI-D-09-00037.1.

7. Kim M-J, Hong S-O. Finite element analysis on stress distribution of maxillary implant-retained overdentures depending on the
Bar attachment design and palatal coverage. J Adv Prosthodont 2016;8:85-93. DOI: 10.4047/jap.2016.8.2.85.

8. Ebadian B, Farzin M, et al. Evaluation of stress distribution of implantretained mandibular overdenture with different vertical restorative spaces: a finite element analysis. Dent Res J 2012;9(6):741-747.

9. Kumar PS, Satheesh KKS, et al. Force transfer and stress distribution in an implant-supported overdenture retained with a hader bar attachment: a finite element analysis. ISRN Dent 2013;2013:369147. DOI: $10.1155 / 2013 / 369147$

10. Vafaei $F$, Khoshhal M, et al. Comparative stress distribution of implant-retained mandibular ball-supported and bar-supported overlay dentures: a finite element analysis. J Oral Implantol 2011;37(4): 421-429. DOI: 10.1563/AAID-JOI-D-10-00057.

11. Satpathy $\mathrm{S}$, Satish Babu CL, et al. Stress distribution patterns of implant supported overdentures-analog vs finite element analysis: a comparative in vitro study. J Indian Prosthodont Soc 2015;15(3): 250-256. DOI: 10.4103/0972-4052.165324.

12. da Silva DP, Cazal C, et al. Photoelastic stress analysis surrounding implant-supported prosthesis and alveolar ridge on mandibular overdentures. Int J Dent 2010;780670. DOI: 10.1155/2010/780670.

13. Raghavendra Reddy K, Thumati P. Influence of implant with different dimensions and designs in ideal stress distribution in bone for application in compromised situations: analysis by three-dimensional finite element method. J Dent Implants 2014;4(2):109-114.

14. Barao VAR, Delben JA, et al. Comparison of different designs of implant-retained overdentures and fixed full-arch implantsupported prosthesis on stress distribution in edentulous mandible-a computed tomography-based three-dimensional finite element analysis. J Biomech 2013;46:1312-1320. DOI: 10.1016/ j.jbiomech.2013.02.008.

15. Feine JS, Carlsson GE, et al. Editorial. J Prosthet Dent 2002;88(2): 123-124. 